\title{
EFFECT OF DIABETES MELLITUS ON GRAFT DISEASE PATTERN AFTER CORONARY ARTERY BYPASS GRAFT SURGERY IN SYMPTOMATIC PATIENTS DETECTED BY MULTI SLICE CORONARY COMPUTED TOMOGRAPHY ANGIOGRAPHY
}

By

\author{
Amr Hazem Mohamed El-Metwally, Islam Shawky Abd El-Aziz and \\ Ashraf Al-Amir Abd El-Fatah
}

Department of Cardiovascular Medicine, Faculty of Medicine, Al-Azhar University

Corresponding author: Amr Hazem Mohamed Elmtwally,

E-mail: hazemamr642@gmail.com

\begin{abstract}
Background: Surgical revascularization of the coronary arteries is one of the most frequent surgical procedures performed worldwide. Although the procedure is one of the major successes of modern medicine, it does not treat the disease underlying the symptoms (atherosclerosis), but only the clinical presentation of coronary artery disease. Multi detector computed tomography (MDCT) accuracy in coronary artery bypass grafting $(\mathrm{CABG})$ patency and stenosis assessment is excellent compared with angiography. Its safety advantages have led to rapidly increasing usage in both native and grafted vessel evaluation.
\end{abstract}

Objective: To evaluate the impact of diabetes mellitus on the patency of arterial and venous grafts after coronary artery bypass surgery assessed by multi slice CT coronary angiography.

Patients and methods: One hundred post CABG patients were included, and divided into two groups: Group A (sixty diabetic patients) from which thirty two had NIDDM (53.3\% of diabetic patients), twenty eight (46.6\% of diabetic patients) had IDDM, and group B (forty non diabetic patients). Patients subjected to our study were symptomatic with recurrent typical chest pain or angina equivalent. All included patients had sinus rhythm, heart rate less than $70 \mathrm{bpm}$, weight less than $150 \mathrm{~kg}$ and serum creatinine $<1.5 \mathrm{mg} / \mathrm{dl}$. Patients were investigated by Seimens Somatom Definition Flash 64- dual source MDCT at least 12 months after the surgery.

Results: The most common risk factor in our studied population was hypertension affecting $55 \%$ of studied population followed by smoking which was prevalent at $54 \%$ of studied population. Comparison of the number of diseased grafts in the two study groups according to hypertension showed a statistically significant difference in group A (diabetic group). Comparison of the number of diseased grafts in the two study groups according to dyslipidemia showed a statistically significant difference in group A. Comparison of the number of diseased grafts in the two study groups according to smoking showed a statistically significant difference in group B (non- diabetic group). 101 arterial grafts had been evaluated for patency, 96 LIMA and 5 radial arteries. There were 59 LIMA in diabetic patients and 37 LIMA in non-diabetic patients evaluated. There was no statistically significant LIMA occlusion in group A and group B. In our study, 141 venous grafts were evaluated for patency: 83 venous grafts in diabetic patients, and 58 venous grafts in non-diabetic patients. Comparison of the two study groups as regards patency of venous grafts showed a statistically significant in group A, and revealed also more occluded grafts at diabetic group. There was a statistically significant graft occlusion with longer duration of diabetes mellitus and higher glycosylated hemoglobin HbAlc. 
Conclusion: Multi-slice CT coronary angiography has an important role in evaluation patency of coronary grafts after coronary artery bypass surgery. Graft occlusions were more common among diabetics compared with non-diabetics. Diabetes was associated with lower vein graft patency but similar arterial graft patency in comparison to non-diabetics. Uncontrolled diabetes mellitus and long duration of disease was found to be a significant predictor for graft occlusion.

Keywords: Diabetes Mellitus, Graft disease pattern, Coronary Artery Bypass Graft surgery, MDCT.

\section{INTRODUCTION}

Coronary artery bypass grafting $(\mathrm{CABG})$ remains one of the most commonly performed major surgical procedures worldwide and the most common procedure performed by cardiac surgeons (D'Agostino et al., 2018).

The reduction or disappearance of angina, the improved tolerability of physical exercise and the overall improvement in quality of life and life expectancy have been the motivations underlying its use since the first the procedure was performed in the 1950 . Although the procedure is one of the major successes of modern medicine, it doesn't eliminate the disease underlying the symptoms (atherosclerosis) only the clinical presentation of coronary artery disease (Cademartiri et al., 2012).

The large number of patients suffering a recurrence of angina after surgical revascularization represents a significant issue in clinical cardiology. Recurrence of angina can be present in association with myocardial ischemia both in previously reperfused and non reperfused regions. These patients should therefore undergo clinical and instrumental monitoring and some cases a repeat procedure is needed, which unfortunately is encumbered by a higher percentage of post procedure complications (Borges et al., 2010).

An important predictor of long-term success in CABG is graft patency. This is especially true in diabetic patients because they are prone to diffuse and rapidly progressive atherosclerosis (Aronson and Edelman, 2010).

Multi-detector computed tomography has become an alternative to coronary angiography to diagnose graft occlusion and stenosis after coronary artery bypass. In addition, multi-detector $\mathrm{CT}$ has the added advantage over traditional angiographic evaluation of simultaneously allowing evaluation for alternate postoperative complications that may also manifest with chest pain and dyspnea and recurrent angina (Khedr et al., 2013).

Multi slice computed tomography (MDCT) is a result of progress spatial resolution through thinner slice collimation and to increased temporal resolution through faster gantry rotation. MDCT angiography is a non-invasive imaging technique that in the scanner technology which led to improved can be performed on ambulatory patients (Hamon et al., 2010).

The introduction of 64-slice MDCT and dual-source CT permitted improved temporal resolution, spatial resolution, and reduction of both cardiac and respiratory motion, leading to improved assessment of arterial and venous graft stenosis and occlusion. Reports on diagnostic accuracy of MDCT in CABG have shown values of sensitivity and specificity over $95 \%$ for the presence of lesions in these vessels. However, the investigation of native 
vessels showed that sensitivity and specificity are significantly lower than in patients with suspected coronary artery disease (Shaw et al., 2012).

The aim of our study was to evaluate the impact of diabetes mellitus on the patency of arterial and venous grafts after coronary artery bypass surgery assessed by multi slice CT coronary angiography.

\section{PATIENTS AND METHODS}

This study included 100 post CABG patients in the span of one year from November 2018 to November 2019 at National Heart Institute, and Al-Hussein University Hospital, and complaining of ischemic symptoms.

All hundred patients were divided into two groups: Group A (sixty diabetic patients) and group B (forty non diabetic patients), and investigated by Seimens Somatom Definition Flash 64- dual source MDCT at least 12 months after the surgery.

\section{Inclusion Criteria:}

Symptomatic post CABG with at least of 12 months from surgery either diabetic or not diabetic.

All symptomatic patients presented with recurrent exertional chest pain or angina equivalent were eligible for inclusion in the study, and fulfilling: Sinus rhythm, their heart rate less than $70 \mathrm{bpm}$ spontaneously or beta-blocker induced, can hold breath for more than 14 seconds, weight less than $150 \mathrm{~kg}$. and serum creatinine $<1.5 \mathrm{mg} / \mathrm{dl}$.

\section{Exclusion Criteria:}

Patients known to have high serum creatinine and not for regular dialysis ( $\mathrm{S}$. creatinine $>1.5 \mathrm{mg} / \mathrm{dl}$ ), patients with invaluable images due to artifacts e.g. obese patients, motion artifacts due to inadequate breath holding or arrhythmia e.g. atrial fibrillation (AF), frequent premature atrial contractions (PVCs), previous coronary stenting, repeated bypass surgery (REDO), patients presented with acute coronary syndrome (ACS), hypersensitivity to iodinated contrast agent and history of allergies or allergic reactions to other medications

All the patients were subjected to the following:

- Personal data collection and risk factors assay such as age, gender, presence or absence of hypertension, diabetes, smoking, dyslipidemia, and to ensure that there was no obstacles to undergo MSCT such as history of bronchial asthma (which would contraindicate the administration of beta blockers).

- Clinical examination including vital signs with general, chest, and cardiac examination.

- 12- Lead ECG: to detect ischemic changes and exclude non sinus rhythm.

- Echocardiography; Variables of left ventricular performance that were measured included LV internal diameter during end-diastole (LVIDd), $\mathrm{LV}$ internal diameter during endsystole (LVIDs), LVEF, left atrial diameter, LV mass, septal wall thickness and posterior wall thickness.

\section{- Routine lab investigations:}

1. Blood glucose level for patients not known to be diabetic: Diabetes was diagnosed according to the criteria 
set by American Diabetes Association (2018): Classic symptoms of hyperglycemia or hyperglycemic crisis, a random plasma glucose $\geq 200 \mathrm{mg} / \mathrm{dl}$. Fasting plasma glucose level of $\geq 126$ $\mathrm{mg} / \mathrm{dl}$. The 2-h plasma glucose (2-h $\mathrm{PG})$ value after a 75 -g oral glucose tolerance test $($ OGTT) $\geq 200 \mathrm{mg} / \mathrm{dl}$. Glycosylated Hemoglobin (HBA1C) of greater than or equal to 6.5.

\section{Serum creatinine.}

3. Lipid Profile.

All patients underwent MDCTA after one year, at least, post CABG using 64dual source Siemens Flash definition scanner. The contrast was injected intravenously and a non-ionic low osmolar contrast was used. The test bolus technique was used. Scanning started after determining the delay time. The entire scans were ECG gated.

MDCT data were evaluated using the transaxial images, as well as other reconstruction modalities; maximal intensity projection (MIP) and curved multiplanar reconstruction (MPR). Each graft was classified as patent (flow visible), occluded, or not analyzable (graft was obscured by a metal ligature clip or because the image quality was poor).

Informed written consent was obtained from every participant.

\section{Statistical Analysis:}

Data were collected, revised, coded and entered to the Statistical Package for the Social Sciences (IBM SPSS) version 20. Descriptive statistics were done for numerical parametric data as mean and minimum \& maximum of the range, while they were done for categorical data as number and percentage. Inferential analysis was done for quantitative variables using independent t-test in cases of two independent groups with parametric data. Inferential analysis was done for qualitative data using Chi square. The confidence interval was set to $95 \%$ and the margin of error accepted was set to $5 \%$. P-value was considered significant when $\mathrm{P} \leq 0.05$.

\section{RESULTS}

This study included 242 grafts from one hundred symptomatic post CABG patients, randomized into group $A(n=60)$ which was diabetic, and group B $(n=40)$ which was non-diabetic, All of them underwent Multi-detector Computed Tomography (MDCT) to evaluate grafts patency.

Comparison of the two study groups as regards age showed a statistically nonsignificant difference $(\mathrm{P}$-value $=$ 0.099). The comparison of the two study groups as regards gender showed a statistically non-significant difference ( $\mathrm{P}$ value $=0.610)$. Comparison of the two study groups as regards prevalence of smoking shows insignificant difference (P-value: 0.512). Comparison of the two study groups as regards prevalence of hypertension showed non-statistically significant difference $(\mathrm{P}$-value $=0.682$ ). Comparison of the two study groups as regards prevalence of dyslipidemia showed non-statistically significant difference $(\mathrm{P}$-value $=0.741)$. 
Comparison of the two study groups according to number of diseased grafts demonstrated a statistically significant difference at the diabetic group (Pvalue $=0.002)$. Number of occluded grafts was more in diabetic group (Table 1).

Table (1): Comparison of the two groups as regards age, gender, smoking, hypertension and dyslipidemia and number of disease grafts

\begin{tabular}{|c|c|c|c|c|c|c|c|}
\hline $\begin{array}{c}\text { Groups } \\
\text { Parameters }\end{array}$ & \multicolumn{3}{|c|}{$\begin{array}{c}\text { Diabetic } \\
\mathbf{N}=\mathbf{6 0}\end{array}$} & \multicolumn{3}{|c|}{$\begin{array}{l}\text { Not Diabetic } \\
\quad \mathrm{N}=40\end{array}$} & P-value \\
\hline \multicolumn{8}{|l|}{ Age: } \\
\hline Range & 37 & - & 82 & 43 & - & 77 & \multirow{2}{*}{0.099} \\
\hline \multirow[t]{3}{*}{ Mean \pm SD } & 58.700 & \pm & 9.367 & 61.750 & \pm & 8.357 & \\
\hline & \multicolumn{2}{|c|}{ Diabetic } & \multicolumn{2}{|c|}{ Not Diabetic } & \multicolumn{2}{|c|}{ Total } & \\
\hline & $\mathrm{N}=60$ & $\%$ & $\mathrm{~N}=40$ & $\%$ & $\mathbf{N}$ & $\%$ & \\
\hline \multicolumn{8}{|l|}{ Gender: } \\
\hline Female & 13 & 21.67 & 7 & 17.50 & 20 & 20.00 & \multirow{2}{*}{0.610} \\
\hline Male & 47 & 78.33 & 33 & 82.50 & 80 & 80.00 & \\
\hline \multicolumn{8}{|l|}{ Smoking: } \\
\hline Non-smoker & 26 & 43.33 & 20 & 50.00 & 46 & 46.00 & \multirow{2}{*}{0.512} \\
\hline Smoker & 34 & 56.67 & 20 & 50.00 & 54 & 54.00 & \\
\hline \multicolumn{8}{|l|}{ Hypertension: } \\
\hline No HTN & 26 & 43.33 & 19 & 47.50 & 45 & 45.00 & \multirow{2}{*}{0.682} \\
\hline HTN & 34 & 56.67 & 21 & 52.50 & 55 & 55.00 & \\
\hline \multicolumn{8}{|l|}{ Dyslipidemia: } \\
\hline Not Dyslipidemia & 34 & 56.67 & 24 & 60.00 & 58 & 58.00 & \multirow{2}{*}{0.741} \\
\hline Dyslipidemia & 26 & 43.33 & 16 & 40.00 & 42 & 42.00 & \\
\hline \multicolumn{8}{|l|}{ Grafts status: } \\
\hline Patent & 89 & 60.54 & 76 & 80.00 & 165 & 68.18 & \multirow{2}{*}{0.002} \\
\hline Occluded & 58 & 39.46 & 19 & 20.00 & 77 & 31.82 & \\
\hline
\end{tabular}

Comparison of the two study groups as regards patency of arterial graft showed insignificant difference in group $\mathrm{A}$ and in group $\mathrm{B} \quad(\mathrm{P}$-value $=0.171)$ while comparison of the two study groups as regards patency of venous grafts showed statistically significant in group $\mathrm{A}$ and revealed also more occluded grafts at diabetic group (P-value $=0.002)$ (Table 2).

Table (2): Comparison of the two study groups according to patency of arterial and venous grafts

\begin{tabular}{|c|c|c|c|c|c|c|c|c|c|}
\hline \multirow{3}{*}{$\begin{array}{c}\text { Grafts } \\
\text { Type }\end{array}$} & \multirow{3}{*}{$\begin{array}{l}\text { Grafts } \\
\text { status }\end{array}$} & \multicolumn{6}{|c|}{ Groups } & \multirow{2}{*}{\multicolumn{2}{|c|}{ Chi-Square }} \\
\hline & & \multicolumn{2}{|c|}{ Diabetic } & \multicolumn{2}{|c|}{ Not Diabetic } & \multicolumn{2}{|c|}{ Total } & & \\
\hline & & $\mathbf{N}$ & $\%$ & $\mathbf{N}$ & $\%$ & $\mathbf{N}$ & $\%$ & $\mathrm{X}^{2}$ & $\begin{array}{c}\mathbf{P} \\
\text { value }\end{array}$ \\
\hline \multirow{2}{*}{ Venous } & Patent & 41 & 49.40 & 44 & 75.86 & 85 & 60.28 & \multirow{2}{*}{9.987} & \multirow{2}{*}{0.002} \\
\hline & Occluded & 42 & 50.60 & 14 & 24.14 & 56 & 39.72 & & \\
\hline \multirow{2}{*}{ Arterial } & Patent & 48 & 75.00 & 32 & 86.49 & 80 & 79.21 & \multirow{2}{*}{1.878} & \multirow{2}{*}{0.171} \\
\hline & Occluded & 16 & 25.00 & 5 & 13.51 & 21 & 20.79 & & \\
\hline
\end{tabular}


Comparison of the number of diseased grafts in the two study groups according to duration after CABG more than 10 years demonstrated non statistically significant difference $(\mathrm{p}$-value $=0.0 .074)$, while comparison of the number of diseased grafts in the two study groups according to duration after CABG less than 10 years was demonstrated statistically significant difference ( $\mathrm{p}$-value $=0.007)$ (Table3).

Table (3): Comparison of the number of diseased grafts in the two study groups according to duration after CABG.

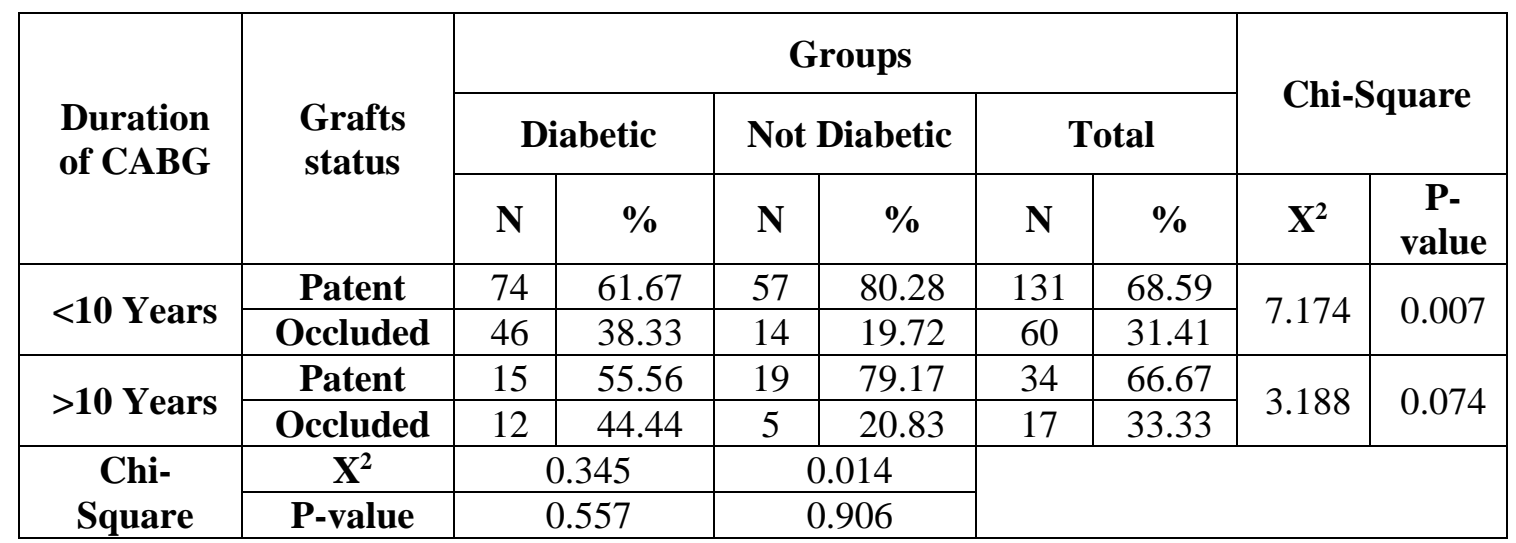

Comparison of the number of diseased grafts according to type of treatment of DM that showed a statistically non- significant difference $(\mathrm{P}$-value $=0.506)$ (Table 4).

Table (4): Comparison of the number of diseased grafts according to type of treatment of DM

\begin{tabular}{|c|c|c|c|c|c|c|c|c|}
\hline $\begin{array}{r}\text { Treatment } \\
\text { of DM }\end{array}$ & \multicolumn{2}{|c|}{ OHG } & \multicolumn{2}{|c|}{ Insulin } & \multicolumn{2}{c|}{ Total } & \multicolumn{2}{c|}{ Chi-Square } \\
\cline { 2 - 8 } Grafts status & $\mathbf{N}$ & $\boldsymbol{\%}$ & $\mathbf{N}$ & $\boldsymbol{\%}$ & $\mathbf{N}$ & $\boldsymbol{\%}$ & \multirow{2}{*}{$\mathbf{X}^{\mathbf{2}}$} & $\begin{array}{c}\text { P- } \\
\text { value }\end{array}$ \\
\hline Patent & 51 & 62.96 & 38 & 57.58 & 89 & 60.54 & & \\
\hline Occluded & 30 & 37.04 & 28 & 42.42 & 58 & 39.46 & 0.442 & 0.506 \\
\hline Total & 81 & 100.00 & 66 & 100.00 & 147 & 100.00 & & \\
\hline
\end{tabular}

Comparison of the number of diseased grafts according to duration of DM demonstrated a statistically significant difference ( $\mathrm{P}$-value <0.001), and revealed that there are more occluded grafts at the diabetic group of duration more than five years (Table 5).

Table (5): Comparison of the number of diseased grafts according to duration of DM

\begin{tabular}{|c|c|c|c|c|c|c|c|c|}
\hline \multirow{3}{*}{ Guration of } & \multirow{2}{*}{\multicolumn{2}{|c|}{$<5$ Years }} & \multirow{2}{*}{\multicolumn{2}{|c|}{$>5$ Years }} & \multirow{2}{*}{\multicolumn{2}{|c|}{ Total }} & \multirow{2}{*}{\multicolumn{2}{|c|}{ Chi-Square }} \\
\hline & & & & & & & & \\
\hline & $\mathbf{N}$ & $\%$ & $\mathbf{N}$ & $\%$ & $\mathbf{N}$ & $\%$ & $\mathbf{X}^{2}$ & $\begin{array}{c}\text { P- } \\
\text { value }\end{array}$ \\
\hline Patent & 50 & 79.37 & 39 & 46.43 & 89 & 60.54 & \multirow{3}{*}{16.348} & \multirow{3}{*}{$<0.001$} \\
\hline Occluded & 13 & 20.63 & 45 & 53.57 & 58 & 39.46 & & \\
\hline Total & 63 & 100.00 & 84 & 100.00 & 147 & 100.00 & & \\
\hline
\end{tabular}


Comparison of the number of diseased grafts according to HBA1c demonstrated a statistically significant difference $(\mathrm{P}-$ value $=0.033)$ in patients with $\mathrm{HbA} 1 \mathrm{c}>7$ and revealed that there were more occluded grafts at diabetic patients with higher HBA1C more than 7 (Table 6).

Table (6): Comparison of the number of diseased grafts according to HBA1c

\begin{tabular}{|c|c|c|c|c|c|c|c|c|}
\hline \multirow{2}{*}{$\begin{array}{l}\text { Grafts } \\
\text { Status }\end{array}$} & $\mathbf{N}$ & $\mathbf{\%}$ & $\mathbf{N}$ & $\mathbf{\%}$ & $\mathbf{N}$ & $\mathbf{\%}$ & $\mathbf{X}^{\mathbf{2}}$ & $\begin{array}{c}\text { P- } \\
\text { value }\end{array}$ \\
\cline { 2 - 9 } & \multicolumn{2}{|c|}{$<$ HbA1c } & \multicolumn{2}{|c|}{$>$ 7 HbA1c } & \multicolumn{2}{|c|}{ Total } & \multicolumn{2}{|c|}{ Chi-Square } \\
\cline { 2 - 9 } & 45 & 70.31 & 44 & 53.01 & 89 & 60.54 & & \\
\hline Patent & 45 & 29.69 & 39 & 46.99 & 58 & 39.46 & 4.528 & 0.033 \\
\hline Occluded & 19 & 63 & 100.00 & 147 & 100.00 & & \\
\hline Total & 64 & 100.00 & 83 &
\end{tabular}

\section{DISCUSSION}

The mean age for the non-diabetic group was $61.75 \pm 8.35$, and the diabetic group was 58.7 \pm 9.36 . The gender predominance was mostly males (in the non-diabetic group they were $82.5 \%$, while in the diabetic group they were $78.3 \%)$. Other studies showed more male patients with a mean age of $62.6 \pm 10.3$ for non-diabetics and $63.5 \pm 9.7$ for the diabetic group (Weiss et al., 2013).

The most common risk factor in our studied population was hypertension affecting $55 \%$ of studied population, correlating with the study done by Sunman et al. (2013), in which hypertension was the most common risk factor affecting $63 \%$ of studied population. In $\mathrm{Li}$ et al. (2011) study smoking was the most common risk factor affecting $60 \%$ of studied population which is not correlated with our study due to different group samples of different studies.

In our study, comparison of the number of diseased grafts in the two study groups according to hypertension showed statistically significant difference in group A, with non-significant difference in group B, this was in agreement with the study done by Muath et al. (2011), where $75 \%$ of hypertensive patients developed graft occlusion. So, hypertension with diabetes mellitus increases risk of graft occlusion. A post hoc analysis of the Clopidogrel after surgery for coronary artery disease (CASCADE) trial was done by Dai et al. (2013), where hypertension correlates with the development of graft hyperplasia and occlusion.

In our study, comparison of the number of diseased grafts in the two study groups according to dyslipidemia showed a statistically significant difference in group A, with statistically non-significant difference in group B. This was in agreement with the study done by Jerzewski et al. (2013), within the CASCADE trial population which demonstrated that lower HDL levels were associated with trends towards more graft occlusions 12 months following CABG. In the study done by Muath et al. (2011) found a strong correlation between high triglycerides, high LDL and graft occlusion.

In our study, 101 arterial grafts had been evaluated for patency, 96 LIMA and 5 radial arteries. There were 59 LIMA in 
diabetic patients and 37 LIMA in nondiabetic patients evaluated. Comparison of the two study groups as regards patency of arterial graft showed no statistically significant difference in group $\mathrm{A}$ and in group B. This was in agreement with Yang et al. (2018) who found that suffering from diabetes mellitus yielded significant higher graft failure of SVG, but not for LIMA graft, correlating with our study. Also, our study was in agreement with Raza et al. (2017) revealed that LIMA patency was stable over time and similar in patients with and without diabetes.

In our study, 141 venous grafts were evaluated for patency, 83 venous grafts in diabetic patients and 58 venous grafts in non-diabetic patients. Our study showed statistically significance in group $\mathrm{A}$, and revealed also more occluded grafts at diabetic group and was in agreement with the study done by Deb et al. (2014). Deb et al. (2014) showed that SV graft patency was lower in diabetics than the nondiabetics. Also our study came in agreement with the study done by Azizi et al. (2016).

In our study, comparison of the number of diseased grafts in the two study groups according to duration of CABG more than 10 years demonstrated non-statistically significant difference. This was in agreement with Raza et al. (2017) which revealed that the long-term patency of bypass grafts was similar between diabetic and non-diabetic patients. However, a study by Ayan et al. (2015). DM was associated with higher graft stenosis and occlusion compared to non-DM in contrast to our study.

In our study, as regard to the type of treatment of DM either (insulin or oral hypoglycemic drug), there was no statistically significant difference at the number of diseased grafts between diabetic patients on insulin and those on oral hypoglycemic drugs, which was in agreement with a study done by Koshizaka et al. (2014). Koshizaka et al. (2014) revealed that there was no significant difference of severity of graft lesion and number of diseased grafts between patients with diabetes requiring insulin and those treated with other therapies.

In our study, the number of diseased grafts is in direct relation to duration of DM and showed a statistically significant difference at the diabetic group of duration more than five years which was in agreement with study done by Saleem et al. (2010) that showed strong correlation between the duration of DM with severity of graft occlusion and coronary artery disease.

In our study, the number of diseased grafts was in-direct relation to glycosylated hemoglobin and showed a statistically significant difference in patients with HbA1c more than 7. This was in agreement with study done by Nystrom et al. (2015) patients undergoing surgical revascularization with a median follow-up of 4.7 years. They showed that increasing levels of $\mathrm{HbA} 1 \mathrm{c}$ resulted in increasing rates of death and major cardiovascular events (MI, heart failure or repeat revascularization). However, our study was in contrast to a previous study done by Lau et al. (2006) who assessed Graft patency by multi slice computed tomographic (CT) angiography and found that poor diabetic control was not 
independent predictor of graft nonpatency.

\section{CONCLUSION}

Multi-slice CT coronary angiography has an important role in evaluation patency of coronary grafts after coronary artery bypass surgery. Uncontrolled diabetes mellitus and long duration of disease was found to be a significant predictor for graft occlusion. Diabetes is associated with lower vein graft patency but similar arterial graft patency in comparison to non-diabetics. Type of treatment of diabetes mellitus has no role in graft patency.

\section{RECOMMENDATION}

In view of the small number of the studied cases and lack of long-term follow-up data, further studies including larger number of patients and focusing on long-term clinical outcomes is recommended.

\section{REFERENCES}

1. Aronson D and Edelman ER. (2010): Revascularization for coronary artery disease in diabetes mellitus: angioplasty, stents and coronary artery bypass grafting. Rev Endocr Metab Disord., 11: 75-86.

2. Ayan M, Saurav A and Kabach A. (2015): Impact of diabetes mellitus on graft patency following coronary artery bypass surgery: a propensity score analysis. J Am Coll Cardiol., 66:110-14.

3. Azizi Z, Ghavidel AA, Mohammadzadeh A and Salehian R. (2016): Short term and long term follow up of coronary artery bypass graft patients by 256-slice multi-detector CT angiography: assessment of patency and predictors of graft occlusion. Journal of the American College of Cardiology, 67(13): 1228-230.

4. Borges JC, Lopes N, Soares PR, Gois AF, Stolf NA, Oliveira SA, Hueb WA and
Ramires JA. (2010): Five-year follow-up of angiographic disease progression after medicine, angioplasty, or surgery. J Cardiothorac Surg., 5:91-96.

5. Cademartiri F, Casolo $G$ and Midiri $M$ (2012): Clinical Applications of Cardiac CT. Section III, Springer, Milano, Pp. 153-163

6. D'Agostino RS, Jacobs JP and Badhwar V. (2018): The Society of Thoracic Surgeons Adult Cardiac Surgery Database: 2018 update on outcomes and quality. Ann Thorac Surg., 105:15-23.

7. Dai U, Al-Atassi T, Kulik A, LeMay M and Ruel M. (2013): The Effect of Clopidogrel Plus Aspirin versus Aspirin Only on Progression of Native Coronary Artery Disease 1 Year After CABG: Analysis From the CASCADE Randomized Trial. Circulation, Circulation, 130:12-18.

8. Deb S, Singh SK and Moussa F. (2014): The long-term impact of diabetes on graft patency after coronary artery bypass grafting surgery: a substudy of the multicenter radial artery patency study. J Thorac Cardiovasc Surg., 148:1246-53.

9. Hamon $M$, Lepage $O$ and Malagutti $P$. (2010): Diagnostic perfor- mance of 16 and 64section spiral CT for coronary artery bypass graft assessment: meta-analysis. Radiology, 247:679-686.

10. Jerzewski, K, Ruel, $M$ and Voisine, $P$. (2013): Does high-density lipoprotein influence the development of saphenous vein graft disease after coronary bypass surgery?: exploratory analysis from the CASCADE trial. J Cardiothorac Surg., 8: 172-77.

11. Khedr SA, Hassaana MA and Allamb MH. (2013): Diagnostic value of MDCT angiography in assessment of coronary artery bypasses graft. The Egyptian Journal of Radiology and Nuclear Medicine, 2: 183-191.

12. Koshizaka M, Lopes RD and Reyes EM. (2015): Long-term clinical and angiographic outcomes in patients with diabetes undergoing coronary artery bypass graft surgery: results from the project of Ex-vivo Vein graft engineering via transfection IV trial. Am Heart J., 169: 175-184. 
13. Lau GT, Ridley LJ, Bannon PG, et al. (2006): Hypertriglyceridemia is associated with early non-patency of coronary bypass grafts. Heart, 92(4):536-538.

14. Li J, Liu Y, Zheng J, Chen Y and Zhang $H$. (2011): The patency of sequential and individual vein coronary bypass grafts: a systematic review. The Annals of Thoracic Surgery, 92(4): 1292-1298.

15. Muath AA, Ali A and Aleinati T. (2011): Clinical characteristics and outcomes of patients with acute coronary syndrome and prior coronary artery bypass grafting in a large Middle Eastern cohort. The Open Cardiovascular Medicine Journal, 5: 196-202.

16. Nyström T, Holzmann MJ and Eliasson B. (2015): Glycemic control in type 1 diabetes and long-term risk of cardiovascular events or death after coronary artery bypass grafting. Journal of the American College of Cardiology, 66(5): 535-543.

17. Raza S, Blackstone EH, Houghtaling PL, Rajeswaran J, Riaz H, Bakaeen FG, Lincoff AM and Sabik JF. (2017): Influence of Diabetes on Long-Term Coronary Artery Bypass Graft Patency J Am Coll Cardiol., 70(5):515-524.

18. Saleem T, Hameedullah $M$, Abdel-Fattah MM and Abbasi AH. (2010): Association of glycosylated haemoglobin level and diabetes mellitus duration with the severity of coronary artery disease. Diabetes and Vascular Disease Research, 5(3): 184-189.

19. Shaw LJ, Cerqueira MD and Brooks MM. (2012): Impact of left ventricular function and the extent of ischemia and scar by stress myocardial perfusion imaging on prognosis and therapeutic risk reduction in diabetic patients with coronary artery disease: Results from the bypass angioplasty revascularization investigation 2 diabetes (BARI 2D) trial. Journal of Nuclear Cardiology, 19(4):658-669.

20.Sunman H, Yorgun H, Canpolat $U$ and Kunak A. (2013): Prognostic value of dualsource multi detector computed tomography coronary angiography in patients with stent implantation. The International Journal of Cardiovascular Imaging, 29(2): 1603-1611.

21. Weiss AJ, Zhao S and Tian DH. (2013): A meta-analysis comparing bilateral internal mammary artery with left internal mammary artery for coronary artery bypasses grafting Ann Cardiothorac Surg., 2(4): 390-400.

22. Yang $L$, Tao $L$ and Zhang $W$, Luo $C$, Huang $\mathbf{Z}$ and Li J. (2018): Midterm Follow-up of Coronary Artery Bypass Grafting with 64-Slice Multi-detector Computed Tomography: Identification of Risk Factors Affecting Graft Patency. Chinese Medical Sciences Journal, 33(2): 69-76. 


\section{تأثير داء السكري على قصور الوصلات للثر ايين التاجية بعد جر احة القلب المفتوح المقيمة بالأشعة المقطعية متعددة المقاطع}

عمرو حازم محمد المتولي, إسلام شوقي عبد العزيز, أشرف الأمير عبد الفتاح قسم أمراض القلب والأوعية الدموية، كلية الطب، جامعة الأزهر

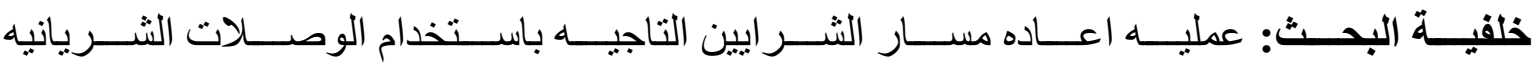

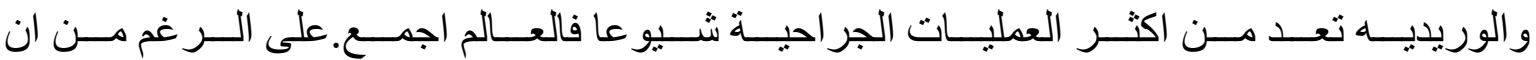

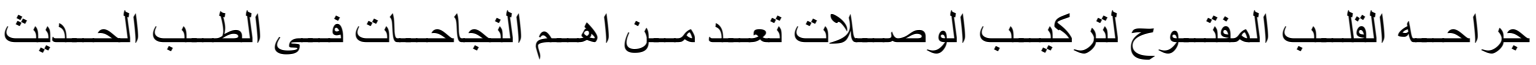

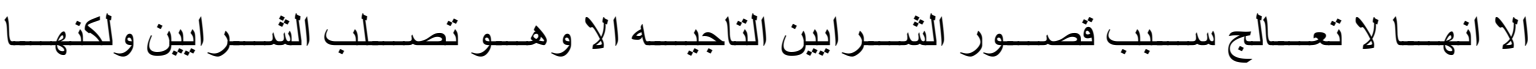

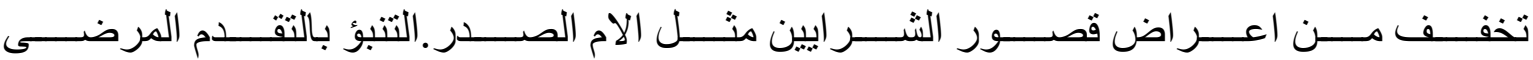

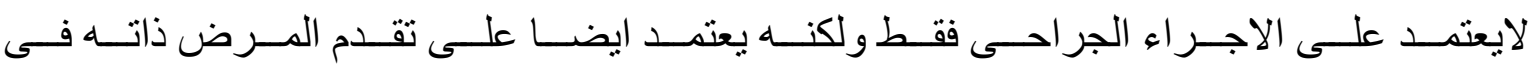

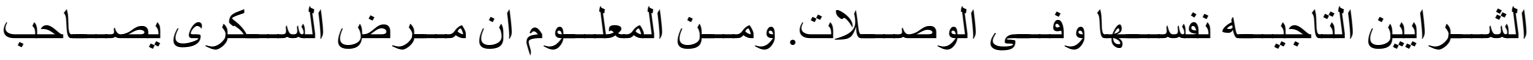

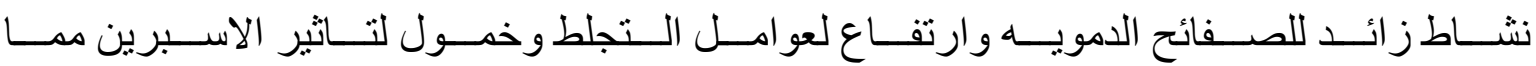
يعطى اثناره لزيادة فنثل الوصلات فى مرضى السكرى.

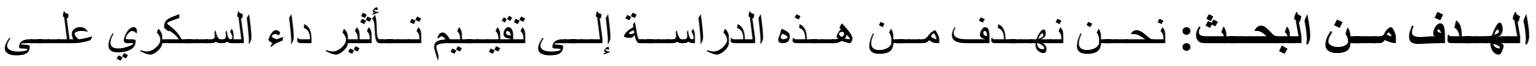

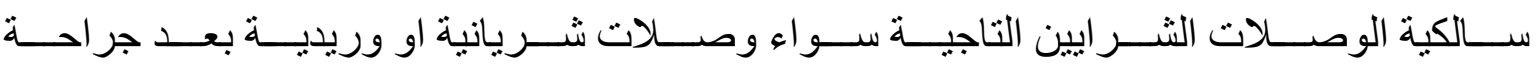
القلب المفتوح مقيمة بالاشعه المقطعية منعددة الكو اشف.

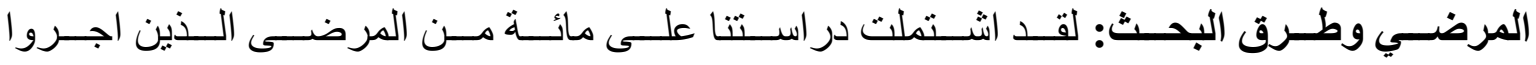

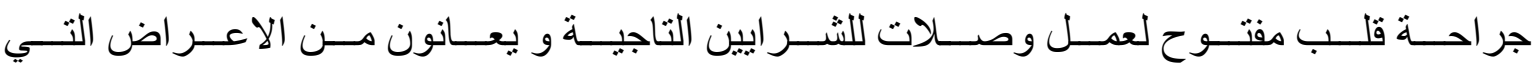

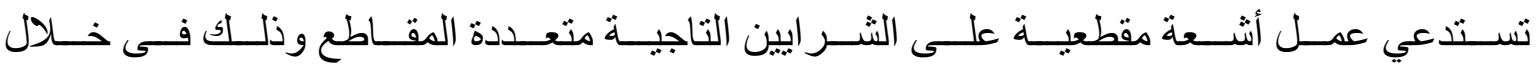

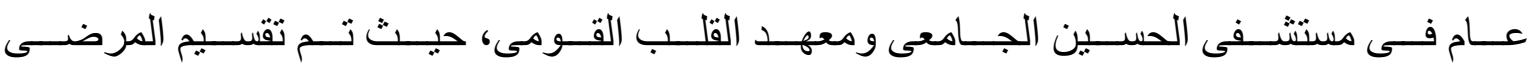

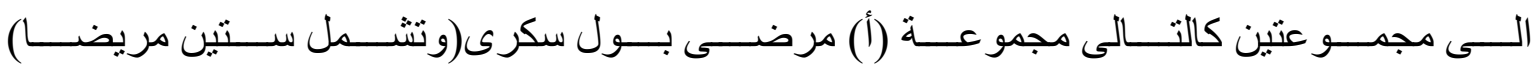

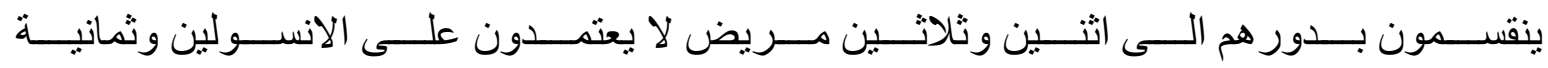

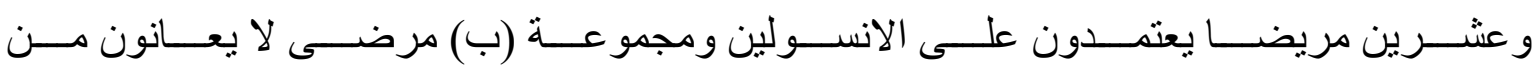
مرض البول السكرى (وتثمل اربعين مريض). 


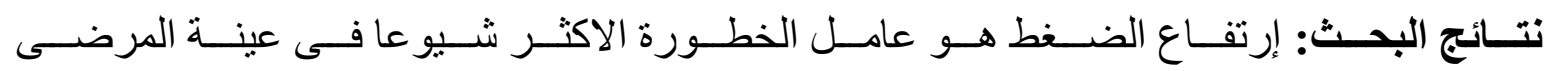

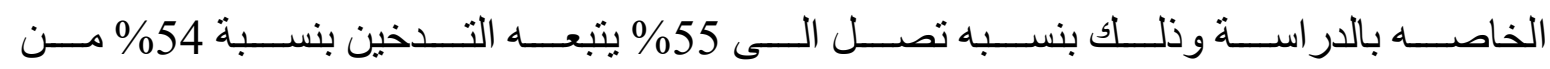

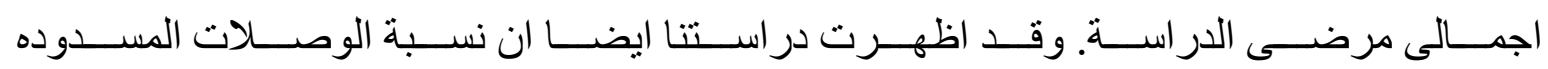

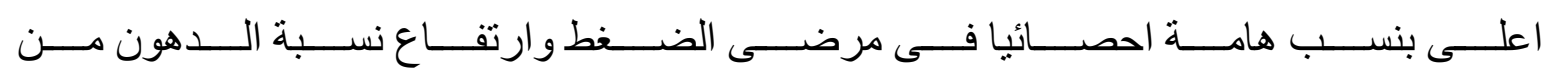

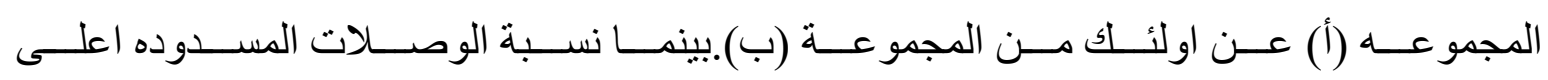

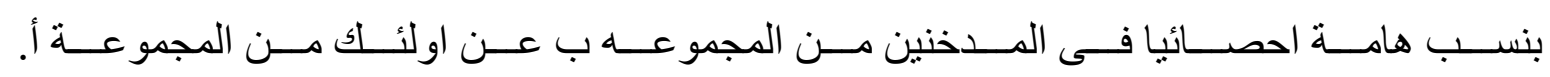

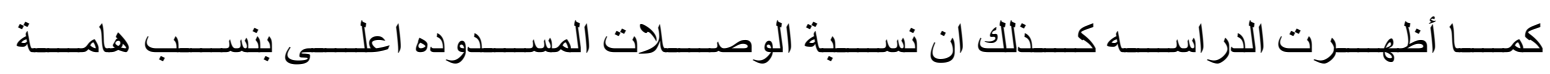

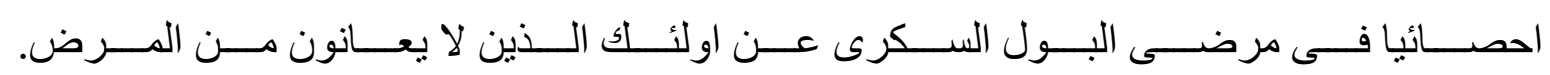

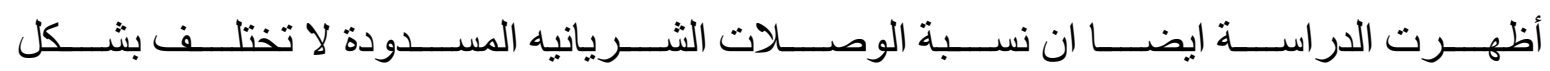

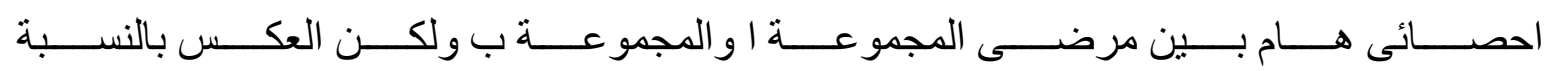

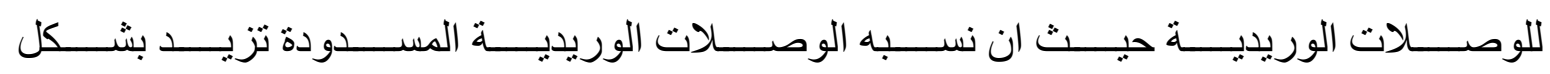
احصائى اكبر فى مرضى المجموعة (أ) عن المجموعة (ب).

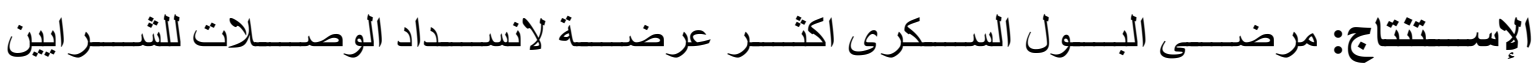

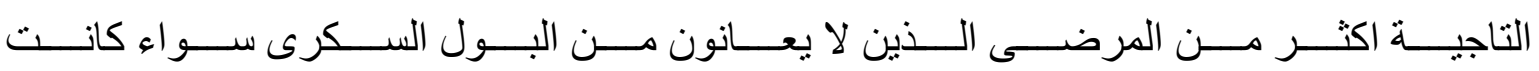

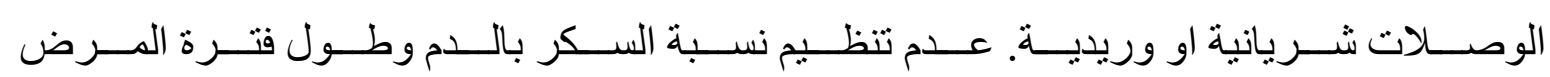

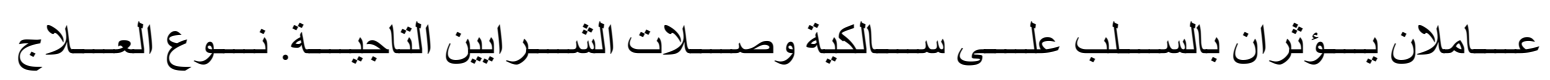

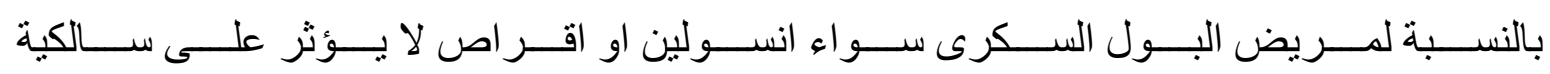

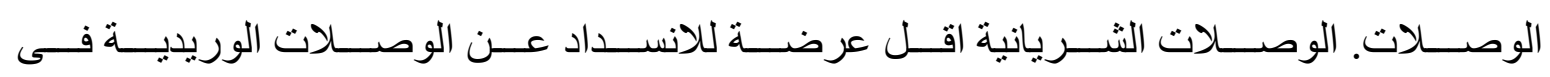
مرضى البول السكرى. 